\title{
Artista em situação pedagógica: o ensinar na prática de Lia Rodrigues
}

\author{
Artist in pedagogical situation: teaching in the \\ practice of Lia Rodrigues
}

Silvia Camara Soter da Silveira ${ }^{1}$

Paola Secchin Braga ${ }^{2}$

\section{RESUMO}

Este artigo aborda a atuação de Lia Rodrigues quando dá aulas, introduzindo a noção de "artista em situação pedagógica". Utilizando-se a categoria "saber docente" na perspectiva de Tardif como referencial teórico, busca-se compreender o modo como a artista articula saberes artísticos e saberes pedagógicos, tomando-se como território de observação o intercâmbio entre alunos e artistas da $\mathrm{La}$ Manufacture e da Escola Livre de Dança da Maré. Constata-se que, para a artista, ensinar e criar se comunicam.

Palavras-chave: Lia Rodrigues. Saberes docentes. Ensino de dança.

\section{ABSTRACT}

This article approaches choreographer Lia Rodrigues' teaching practice, introducing the concept of "artist in pedagogical situation". Using Tardif's "teaching knowledges" category as a theoretical background and taking as observation the territory a student and artist exchange between La Manufacture and the Escola Livre da Dança da Maré, we seek to understand how this artist articulates artistic and pedagogical knowledges. We conclude that for her there is a communication process between teaching and creating.

Keywords: Lia Rodrigues. Teaching knowledges. Dance teaching.
1.

Professora Adjunta da Faculdade de Educação da Universidade Federal do Rio de Janeiro. ORCID: https://orcid.org/ 0000-0002-9760-8551 Contato: ssotersilvia@gmail.com 2.

Doutora em Dança pela Universidade Paris 8. Professora colaboradora no Programa de Pós-Graduação em Estudos Contemporâneos das Artes, da Universidade Federal Fluminense. ORCID: http://orcid.org/ oooo-0003-0698-4461 Contato:

paolasecchinbraga@gmail.com 
Introdução

No contexto mundial atual, especialmente na Europa, podemos observar a tendência a convidar artistas para que intervenham em programas de formação em artes nas universidades, ateliês e escolas $^{3}$. Nesses casos, os artistas convidados assumem a função de professor, ainda que temporariamente, e participam de modo direto na formação de jovens, com quem partilham seus saberes singulares. Se para alguns artistas essa "entrada em situação pedagógica" já é parte constitutiva de suas práticas regulares e percebida como algo natural, para outros, ela é vivida como problemática pela consciência de que os saberes artísticos que detêm são de natureza distinta dos saberes pedagógicos necessários para se ensinar. Sem necessariamente terem passado por programas de formação pedagógica, os artistas em situação pedagógica buscam, então, modos próprios de articulação entre seus saberes artísticos e pedagógicos.

Compreendemos o "artista em situação pedagógica"4 como aquele que tem como identidade principal a de artista - neste caso, um artista da dança - que trabalha como coreógrafo e/ou intérprete na maior parte do tempo, mas que também se coloca na função de professor, sem ter necessariamente passado por cursos de formação de professor de dança. $\mathrm{O}$ artista em situação pedagógica não tem a docência em dança como principal eixo de atuação profissional ${ }^{5}$.

Analisaremos neste artigo como, no caso da dança, se dá esta articulação entre os diferentes saberes e sua partilha. Para tal, tomaremos como exemplo a atuação da coreógrafa Lia Rodrigues ${ }^{6}$, a relação entre seus saberes artísticos e seus saberes pedagógicos, e a forma como ela os compartilha com seus estudantes; em suma, como esta artista da dança atua quando colocada em situação pedagógica. Como foram/são edificados os saberes que mobiliza quando ensina? Qual a natureza destes saberes? Num primeiro momento, identificaremos por meio de entrevistas feitas com a coreógrafa e seus estudantes, bem como por meio da observação de suas oficinas, as relações engendradas entre a criação e o ensinar; em seguida, apontaremos quais seriam as estratégias de ensino presentes na atuação de Lia Rodrigues. Optamos, neste artigo, por trazer as vozes dos múltiplos participantes desse intercâmbio, buscando a polifonia como forma de destacar as relações construídas nesse processo.

\section{Contexto}

No período entre dezembro de 2016 e julho de 2017, foi desenvolvido um projeto de intercâmbio entre estudantes da La
3.

Escolas de formação em dança como a P.A.R.T.S./ Bruxelas, a Salzburg Experimental Academy of Dance SEAD/Salzburg, a Hochschulübergreifendes Zentrum Tanz (HZT), em Berlin, e o programa de bacharelado da La Manufacture, Haute École des arts de la scène, em Lausanne, são exemplos de instituições que contam regularmente com a intervenção de artistas como parte importante do programa de formação.

4.

A categoria "artista em situação pedagógica" está sendo proposta em pesquisa realizada pelas autoras deste artigo em colaboração com La Manufacture, Haute École des arts de la scène, em Lausanne, em ocasião de projeto de intercâmbio entre estudantes da La Manufacture e da Escola Livre de Dança da Maré (ELDM).

5. Trata-se aqui de um enfoque diferente do abordado por Marques (2014), quando revê o termo artista/docente cunhado em sua tese de doutorado, na qual define o termo como: "[...] aquele que, não abandonando suas possibilidades de criar, interpretar, dirigir também tem como função e busca explícita a educação em seu sentido mais amplo. Ou seja, abre-se a possibilidade de que processos de criação artística possam ser revistos e repensados como processos também explicitamente educacionais" (MARQUES, 1999). Nosso enfoque se diferencia igualmente do de Mundim (2014), quando fala da artista com uma prática docente consolidada dentro das universidades. 6.

Lia Rodrigues, coreógrafa, diretora da Escola Livre de Dança da Maré (ELDM): nascida em São Paulo, onde estuda balé clássico e História na Universidade de São Paulo (USP), ela participa do movimento de dança contemporânea desta cidade nos anos 1970. Trabalha na companhia de Maguy Marin de 1980 a 1982. Ao regressar ao Brasil, cria a Lia Rodrigues Companhia de Danças, em 1990, no Rio de Janeiro, com atividades contínuas de pesquisa, criação, aulas e ensaios. Em 1992, ela cria e dirige durante 14 anos o Festival Panorama, o mais importante festival de dança contemporânea do país. Desde 2004, sua companhia desenvolve ações pedagógicas e artísticas no Complexo da Maré, no Rio de Janeiro, em parceria com a ONG Redes de Desenvolvimento da Maré. Desta colaboração, nasce o Centro de Artes da Maré (CAM), em funcionamento desde 2009 e a Escola Livre de Danças da Maré (ELDM), que abre suas portas em outubro de 2011. Durante 40 anos de vida profissional e artística, Lia Rodrigues se dedica não somente à formação e à criação artística, mas também à pedagogia sob forma de ateliês e seminários. Unindo militância e utopias, ela acredita na sinergia entre a arte e os processos sociais. Ela recebe do governo francês a medalha Chevalier dans l'Ordre des Arts et des Lettres, e da Holanda o Prince Claus Award. Na França, ela cria em 2005 uma das fábulas de La Fontaine e, em 2007, Hymnen para o Centro Coreográfico Nacional Ballet de Lorraine. Entre suas criações recentes, citamos Aquilo de que somos feitos (2000), Formas Breves (2002) Incarnat (2005), Chantiers poétiques (2008), Pororoca (2009), Piracema (2011), Pindorama (2013) e Para Que O Céu Não Caia (2016). 
Manufacture, Haute École des arts de la scène $e^{7}$ e da Escola Livre de Dança da Maré (ELDM) ${ }^{8}$, envolvendo a colaboração de seus diretores Lia Rodrigues e Thomas Hauert ${ }^{9}$. O intercâmbio se realizou em duas etapas: em primeiro lugar, em dezembro de 2016, dez alunos da ELDM estiveram na La Manufacture, em Lausanne; em seguida, em abril 2017, a turma do terceiro ano da escola suíça viajou para o Brasil, para uma residência no Centro de Artes da Maré (CAM). Desta forma, tornou-se possível partilhar, em um país como no outro, territórios de pesquisa e criação. Os ateliês artísticos foram ministrados pelos diretores-pedagogos-coreógrafos de cada instituição. O intercâmbio entre os dois artistas e as duas escolas apresentou-se como um campo fértil para o desenvolvimento de uma pesquisa realizada pelas autoras, a convite do Departamento de Pesquisa da La Manufacture, Haute École des arts de la scène, entre dezembro de 2016 e dezembro de 2017. A pesquisa tem por objetivo compreender de que forma se dá a articulação entre os saberes artísticos e pedagógicos no trabalho desses dois coreógrafos - dois artistas colocados em situação pedagógica ao longo do projeto de intercâmbio entre as duas instituições. Trata-se de conhecer o processo de edificação dos saberes artísticos e pedagógicos de cada artista, de aprofundar a reflexão a respeito deste binômio, e de tentar compreender a concepção dos profissionais em questão com relação à formulação de programas para a formação de artistas em dança atualmente, nos contextos da Suíça e do Brasil. O presente artigo se debruça sobre parte desta pesquisa: os saberes de Lia Rodrigues, sua edificação e a relação entre o criar e o ensinar em sua prática profissional.

Trabalhando há alguns anos no cruzamento entre criação artística e prática pedagógica, a vida profissional de Lia Rodrigues se divide entre a criação artística, foco principal de suas atividades, e a formação de jovens artistas a partir de distintas frentes como: a animação de ateliês, aulas regulares em escolas e a direção de uma escola de formação de artistas da dança. Nos últimos anos, ela foi professora convidada em diversos programas de formação inicial e continuada de artistas na Europa, como: o Programa Gulbenkian de Criatividade e Criação Artística e o Fórum Dança, ambos em Lisboa, Portugal (2005); o programa Education Acts! do Tanzquartier em Viena, Áustria (2006); o projeto residências da Fundação Gulbenkian, Lisboa (2007); o programa ESSAIS de pós-graduação da École Supérieure du Centre National de Danse Contemporaine d'Angers, França (2009); o programa da P.A.R.T.S., criada por Anne Teresa De Keersmaeker, Bruxelas, Bélgica (2011); o curso regular da École Supérieure du Centre National de Danse Contemporaine d'Angers, França (2012); o curso de formação avan-
7. Reunindo num mesmo local formações em teatro e dança, $L a$ Manufacture oferece um contexto de ensino superior das Artes da Cena único na Europa francófona. Localizada em Lausanne, Suíça, verdadeira "escola-laboratório", La Manufacture oferece aos jovens artistas um espaço de criação e de experimentação, permitindo que adquiram e desenvolvam as bases de seu ofício, explorando as questões teóricas e práticas da criação artística. Em outra vertente de trabalho, esta instituição apoia e desenvolve pesquisas em relação direta com as questões da criação contemporânea no campo das artes performativas.

8.

A Escola Livre de Dança da Maré se inscreve num projeto mais amplo: Centro de Artes da Maré. Concebido enquanto espaço de criação, formação e difusão das artes, com um foco particular na dança contemporânea, o centro se tornou uma verdadeira referência de equipamento cultural aberto a todos os públicos, superando a segmentação dos diferentes territórios da cidade do Rio de Janeiro no que toca ao direito de acesso às artes. O CAM é o resultado de uma parceria entre a Lia Rodrigues Companhia de Danças e a Redes de Desenvolvimento da Maré. 9.

Thomas Hauert, coreógrafo, responsável pelo Bacharelado em Dança da La Manufacture: dançarino e coreógrafo suíço, desenvolveu uma escrita baseada na improvisação. Depois de trabalhar com Anne Teresa de Keersmaeker, Gonnie Heggen, David Zambrano e Pierre Droulers, funda sua própria companhia, ZOO, em 1988. Cocomitante ao seu trabalho junto à ZOO, Hauert é convidado a criar peças para a P.A.R.T.S., o Trinity Laban Conservatoire of Music and Dance, o Ballet de Zurich, o Toronto Dance Theatre e a Candoco. Desde 2012, participa do projeto Motion Bank dirigido pela Forsythe Company e a Ohio State University. Em 2013, é nomeado responsável acadêmico do Bacharelado em Dança Contemporânea, criado junto à $L a$ Manufacture, Haute école des arts de la scène, em Lausanne. A nova formação é inaugurada em setembro de 2014 . 
çada para alunos do PEPCC do Fórum Dança em Lisboa, Portugal (2014); o programa de Mestrado (Exerce) do Centre Chorégraphique National de Montpellier, França (2017); o Valeska Gert Guest Professorship da Akademie der Künste, em Berlin, Alemanha (2017); além do Bachelor Danse da La Manufacture (2016), já citado. ${ }^{10}$

No Rio de Janeiro, Lia Rodrigues criou em 2011 e dirige até a presente data a Escola Livre de Dança da Maré, que conta com um núcleo de formação intensiva em dança para jovens moradores da Maré, uma favela carioca onde vivem 135 mil habitantes. Para além da escola, Lia Rodrigues afirma, em diversas ocasiões, que também o trabalho junto à sua companhia de dança - a Lia Rodrigues Companhia de Danças - possui um importante viés de formação, uma vez que esta acolhe como integrantes intérpretes jovens e pouco experientes, que se desenvolvem técnica e artisticamente no seio da companhia, ao longo de sucessivos processos de criação, ensaios e performances ${ }^{11}$.

O trabalho artístico de Lia Rodrigues tem sido objeto de várias pesquisas acadêmicas em que se destacam Pedalino (2010), desenvolvida no Departamento de Dança da Universidade de Paris 8, Steuernagel (2012), desenvolvida Departamento de Estudos da Performance da New York University, e Pavlova (2015), desenvolvida no Programa de Pós-graduação de Artes da Cena da Universidade Federal do Rio de Janeiro. Estas três pesquisas refletiram sobre aspectos importantes do trabalho dessa artista a partir da análise de obras (PEDALINO, 2010) e da sua relação com o contexto no qual trabalha regularmente desde 2005, a favela da Maré (STEUERNAGEL, 2012; PAVLOVA, 2015). Ainda que alguns desses trabalhos acadêmicos mencionem a dimensão de formação de artistas através do trabalho de Lia Rodrigues, nenhuma pesquisa se debruçou, até o presente momento, sobre a articulação dos saberes artísticos e pedagógicos na prática profissional desta coreógrafa.

\section{Aporte teórico}

A categoria "saber docente" pela perspectiva de Tardif (2012) servirá de referencial principal para se compreender o modo como cada artista em situação docente articula saberes artísticos e saberes pedagógicos. Ainda que a artista em questão não seja docente de profissão, acreditamos que a concepção de Tardif sobre a natureza, a origem e a temporalidade dos distintos saberes mobilizados pelos professores traz elementos importantes para a compreensão da relação entre os saberes artísticos e os saberes pedagógicos de artistas quando dão aulas.
10.

www.liarodrigues.com . Acesso em 29 de outubro de 2017.

11.

Para uma discussão mais aprofundada, indicamos SOTER, S., PAVLOVA, A. Escola Livre de Dança da Maré in Rio de Janeiro: a ground to share. In: BUTTERWORTH, J., WILDSCUT, L. Contemporary Choreography: A Critical Reader. Londres \& Nova Iorque: Routledge, 2017, p. 268-278. 
Saberes de professores

Como tratado por Tardif, Borges e Pimenta (TARDIF, 2012; BORGES, 2002; PIMENTA, 2012), os saberes mobilizados pelos professores, independentemente de sua área de conhecimento, vão além daqueles abordados em seus cursos de formação universitária. Diversas pesquisas sobre a formação de docentes, que foram realizadas a partir de década de 1990, buscaram compreender as práticas pedagógicas, considerando os professores como mobilizadores de saberes profissionais variados. Saberes, estes, que se constituem e se transformam ao longo da vida, por meio das experiências e da formação de cada um, assim como de sua trajetória profissional (NUNES, 2001).

A categoria saber docente surge para tentar "dar conta da complexidade e especificidade do saber constituído no (e para o) exercício da atividade docente e da profissão" (MONTEIRO, 2001, p. 130). Para Tardif (2012), é impossível isolar o saber docente do contexto no qual seu trabalho se dá e de suas condicionantes. Para se compreender os saberes mobilizados pelos professores em seu trabalho, faz-se necessário situá-los: "O saber é sempre o saber de alguém que trabalha alguma coisa, no intuito de realizar um objetivo qualquer" (TARDIF, 2012, p. 11). Assim, esse "alguém" específico - que tem uma trajetória singular - apropriou-se de "alguma coisa" no intuito de realizar um "objetivo específico". Tardif torna claro que "o saber dos professores é o saber destes, e está relacionado com a pessoa e a identidade, com a sua experiência de vida e com a sua história profissional, com as suas relações com os alunos em sala de aula e com os outros atores escolares na escola, etc." (TARDIF, 2012, p. 11). Ele destaca, ainda, que no cerne de sua abordagem estão a natureza e as fontes dos saberes, sua "proveniência social" (TARDIF, 2012, p. 62), assim como a dimensão temporal da edificação destes saberes. A origem dos saberes, sua natureza, o momento em que emergem e o modo como evoluem estão mesclados e interligados, já que têm suas raízes na trajetória pré-profissional, na formação inicial e continuada e ao longo de toda a trajetória profissional singular desse docente. Os saberes também são desenvolvidos no próprio exercício da profissão.

Assim, o saber do professor é ao mesmo tempo único, plural e temporal. Único porque está alicerçado nas trajetórias deste professor e não de outro. Plural, pois é tecido por fios específicos e distintos. Finalmente, é temporal, já que se constitui em momentos diferentes da vida pessoal e profissional e segue se desenvolvendo ao longo de sua trajetória de vida. 
Para Tardif, no saber docente, além das marcas da trajetória pré-profissional, se tramariam saberes distintos: os saberes da formação profissional, os saberes disciplinares, os saberes curriculares e os saberes da experiência.

As instituições de formação de professores são o lugar onde os docentes em formação entram em contato com os saberes da formação profissional, isto é, as ciências da educação, as teorias e tendências pedagógicas que norteiam as práticas docentes - o que Tardif nomeia como saberes pedagógicos. A estes, ainda ao longo da formação inicial, são articulados os saberes disciplinares, ligados às disciplinas de referência. Eles "correspondem aos diversos campos de conhecimento, aos saberes que dispõe a nossa sociedade, tais como se encontram hoje integrados nas universidades, sob a forma de disciplinas, no interior de faculdades e cursos distintos" (TARDIF, 2012, p. 38). Já os saberes curriculares se materializam nos programas escolares, se manifestam por meio dos objetivos de ensino, dos conteúdos e métodos e dos planejamentos com os quais os docentes aprendem a lidar. Segundo Tardif, manifestam o modo como a escola seleciona e hierarquiza "os saberes sociais por ela definidos, [...] modelos da cultura erudita e de formação para a cultura erudita" (TARDIF, 2012, p. 38). Os saberes da formação profissional (os da ciência da educação e os pedagógicos) e os saberes disciplinares são incorporados ao longo da formação inicial do docente, no caso dos docentes de profissão. Já os saberes curriculares são adquiridos ao longo da carreira profissional, no contexto da escola.

Tardif identifica ainda uma quarta categoria de saberes, que nos interessa especialmente no contexto deste artigo: os saberes experienciais - saberes práticos, que nascem na experiência e amadurecem no trabalho do docente. Vão além dos saberes desenvolvidos nas instituições de formação e dos currículos. Alicerçadores, são saberes práticos e não saberes sobre as práticas, constituindo-se como os "fundamentos de suas competências" (TARDIF, 2012, p. 48) e como "a cultura docente em ação" (TARDIF, 2012, p. 49). Surgem da dificuldade e, muitas vezes, da impossibilidade que os docentes têm em contar apenas com os saberes disciplinares, curriculares e da formação profissional, uma vez em situação concreta de trabalho. Ao iniciarem suas carreiras, os professores sofrem um "choque com a realidade", deparando-se com os limites de seus saberes e com lacunas que precisam preencher para dar conta da prática docente. São, então, levados a desenvolver saberes próprios, oriundos de suas práticas cotidianas, que virão a ancorar seu trabalho.

Os saberes conquistados na trajetória pré-profissional, aqueles edificados anteriormente à formação inicial, inclusive os saberes 
do ter sido aluno, são vistos por Tardif (2012) e por Pimenta (2012) como tendo um grande peso na constituição dos saberes docentes. Tardif afirma que

[...] há muito mais continuidade do que ruptura entre o conhecimento profissional do professor e as experiências pré-profissionais, especialmente as que marcam a socialização primária (família e ambiente de vida), assim como a socialização escolar enquanto aluno. (TARDIF, 2012, p. 72)

O peso do saber advindo da vivência na educação básica seguirá ao longo da vida do docente e, frequentemente, esse saber não será abalado pela formação universitária (TARDIF, 2012, p. 20).

Guardando em mente os pontos explicitados acima, prosseguiremos relacionando-os ao discurso de Lia Rodrigues sobre sua prática profissional, enquanto artista criadora e artista em situação pedagógica.

\section{Edificação dos saberes e trajetória pré-profissional - concepção de ensino de dança}

Com formação em dança clássica e participando em seguida da cena de dança contemporânea, Lia Rodrigues começa a dar aulas na década de 1970, em São Paulo, cidade onde nasceu. Segundo ela, dar aulas foi uma constante em sua vida profissional desde cedo. Inicialmente, deu aulas de balé clássico e, depois, de dança contemporânea, como ela mesma diz, entendendo a "dança contemporânea, [como] uma técnica"12.

A questão da transformação da compreensão do que é uma aula de dança é importante neste contexto. Lia declara que aprendeu técnicas de dança e que, no início, era isso que ensinava em suas aulas. Sua compreensão inicial do que se transmitia numa aula de dança era a técnica, uma técnica ${ }^{13}$. No início de sua vida profissional, as aulas que dava eram fortemente marcadas pela sua experiência como aluna, como já anunciou Tardif. Contudo, isto foi se transformando, como podemos ver neste trecho da entrevista que a coreógrafa concedeu a Silvia Soter:

Naquela época, há muitos anos, eu imaginava que a aula fosse ligada ao ensino de uma técnica específica para se ter um desempenho físico [melhor]. [...] eu não entendia que aquilo era um aprendizado, ou que eu estava aprendendo a ser artista, [...] tinha algumas coisas que nós criávamos entre nós, mas eu nunca ligava isso a um aprendizado... Eu entendo hoje o aprendizado como uma coisa muito mais ampla do que aprender uma técnica. É aprender a
12.

Entrevista concedida a Silvia Soter. Lausanne, 9 de dezembro 2016.

13.

Vale ressaltar que, no período da formação de Lia Rodrigues, as possibilidades de estudo formal na dança eram restritas, não havia muitas opções. Até 1984, existiam somente dois cursos superiores em dança, um na Bahia e o outro no Paraná. Veremos ao longo deste artigo que os saberes pedagógicos da artista foram desenvolvidos por meio de outros conhecimentos e pautados principalmente na experiência, o que se reflete em algumas de suas escolhas, e especialmente na relação entre criação e metodologia de ensino. 
ser artista, aprender a estar no mundo, aprender várias coisas que foram entrando no meu entendimento do que é dar uma técnica ${ }^{14}$.

Vemos, já neste primeiro trecho da entrevista, como as experiências de sua trajetória pré-profissional como aluna de dança e, depois, enquanto bailarina, determinaram seu entendimento do que seria dar uma aula de dança. Entendemos os conhecimentos técnicos em dança clássica, moderna e contemporânea adquiridos pela, então, estudante de dança como saberes disciplinares, incorporados ao longo de uma trajetória pré-profissional e relacionados a disciplinas de referência. Os saberes disciplinares correspondem aos diversos campos de conhecimento - do conhecimento específico da dança ocidental, neste caso integrados na experiência de Lia-estudante-de-dança, não em universidades, mas nas escolas da dança que frequentou. É a esses conhecimentos que ela recorre em primeira instância, ao começar a dar aulas. Sua compreensão de uma aula de dança é baseada no que viveu em sua trajetória pré-profissional, dentro dos espaços de educação não formal de ensino da dança em São Paulo, e é sobre ela que Lia-professora-iniciante calca a preparação das aulas que ministra. Sem intenção de se tornar professora, mas já sendo convidada a dar aulas em diversos locais, as perguntas que Lia Rodrigues se fazia eram recorrentemente as mesmas: "dar aula de quê, neste momento da minha vida? De balé clássico? De dança contemporânea? O que é dar aula de dança contemporânea?"15.

À medida que avança em sua carreira, outras experiências vêm acrescentar elementos de reflexão à sua prática. Seu trabalho, ainda enquanto bailarina, junto à coreógrafa francesa Maguy Marin, na criação da peça May B (1981), se coloca como divisor de águas. Mesmo sem ter tido consciência naquele momento, Lia afirma a importância de ter participado do trabalho:

[...] quando eu vim para a França, minhas experiências eram ainda dessa natureza [técnica]. Eu não entendia, como eu entendo agora, que ali estava aprendendo algo que era tão precioso, como trabalhar numa companhia. Eu não entendia que aquilo era um aprendizado. Ou que eu estava aprendendo a ser artista. [...] Mas eu acho que quando eu fiz o May B, eu não tinha esse entendimento, como, olhando agora, para trás, vejo que ali foi uma verdadeira escola pra mim $^{16}$.

Vemos claramente neste trecho que a experiência de dançar em uma companhia profissional teve uma dimensão formativa, foi "uma verdadeira escola", um modo de se formar enquanto
14.

Entrevista concedida a Silvia Soter. Lausanne, 9 de dezembro 2016.

15

Entrevista concedida a Silvia Soter. Lausanne, 9 de dezembro 2016.

16.

Entrevista concedida a Silvia Soter. Lausanne, 9 de dezembro 2016. 
artista. Mesmo que não tenha tido consciência disto na ocasião, o divisor de águas operou uma mudança na sua compreensão, e Lia-artista foi transformada por essa experiência.

Segundo Tardif, os saberes experienciais emergem no momento em que os professores entram em contato com a realidade e se deparam com a impossibilidade de lidar com ela apenas ancorados nos saberes desenvolvidos anteriormente. Diante das lacunas em sua formação, e para dar conta da prática docente, desenvolvem saberes próprios, alicerçados em suas experiências em sala de aula, na troca com seus pares, no acúmulo de tentativas, erros e acertos, e esses saberes, os da experiência, passam a ser a base de suas práticas como docentes.

Mais tarde em seu percurso, quando já tinha criado sua companhia e faziam apresentações, Lia Rodrigues passou a receber constantemente convites para ministrar workshops. Foi nesse momento que a questão da compreensão do que é uma aula de dança se tornou, de fato, uma preocupação: como preparar algo ligado ao trabalho coreográfico que desenvolvia, que estava sendo levado à cena naquele momento? Ela dá exemplo de como foi pensado um dos workshops iniciais:

Por exemplo, tinha um workshop que eu dei durante muito tempo, em várias viagens, ligado ao Catar. ${ }^{17}$ Então, eu inventei um negócio que era pegar as Parlendas ${ }^{18}$, dividir em ritmos, criar em torno delas. Eu comecei a juntar um pouco... eu tentava fazer um aquecimento, que eu achava também [necessário]. Daí, começava a dividir em grupos, e as pessoas começavam a criar, eu começava a combinar, isso com aquilo ${ }^{19}$.

Vemos indicada, na fala de Lia Rodrigues, a ligação do conteúdo do workshop a ser ministrado à obra que seria apresentada na ocasião, a criação determinando a maneira de se conceber o workshop, o mesmo pensamento permeando as atividades artística e docente. Ela mesma declara explicitamente que a atividade da companhia e o desenvolvimento de workshops caminhavam e, ainda hoje em dia, caminham lado a lado.

Alguns projetos foram determinantes para que a artista e sua companhia consolidassem estratégias de ensino que pudessem se adaptar a públicos diversos. Dentre eles, estão um projeto dirigido a professores da rede pública de ensino em vários lugares do Brasil que ocorreu no final dos anos 1990, e um outro que teve alunos da rede pública de ensino do Rio de Janeiro como público alvo. Sobre o primeiro, a artista lembra que a preparação destas oficinas impôs que ela e sua equipe criassem "uma metodologia que fizesse sentido para o trabalho da companhia e que fizesse
17.

Obra criada por Lia Rodrigues, em parceria com João Saldanha, em 1988.

18.

A obra Catar foi desenvolvida a partir de improvisações sobre a ação de catar, tendo como referência "uma Parlenda, que é uma rima infantil para divertir, ajudar a memorizar ou escolher quem fará tal ou qual brincadeira" (Fonte: RODRIGUES, Lia. Catar. In: Lia Rodrigues Companhia de Danças. Disponível em: <www. liarodrigues.com/page2/styled-8/ styled-27/index.html>. Acesso em: 7 nov. 2017).

19.

Entrevista concedida a

Silvia Soter. Lausanne, 9 de dezembro 2016. 
sentido, igualmente, para as pessoas com as quais iria(m) trabalhar"20. Como ela destaca:

Eram pessoas que não tinham nenhum contato com a dança, que não tinham contato com uma prática corporal, de cidades muito distantes dos centros, mais, assim, onde você tem contato com arte. E, também, em lugares sem nenhum espaço físico para aquilo. Era uma adaptação completa. [...] A gente tinha uma série de exercícios de criação que a gente tinha que fazer. Depois, a gente criou uma pequena coreografia que fazíamos no final. Cada grupo, que ia para uma cidade, tinha um mesmo jeito de provocar naqueles corpos um movimento, alguma coisa que eles se sentissem criando, que era essa a ideia. E, depois, tinha uma coreografia, a gente inventou uma coisa que eles pudessem se sentir participantes. Essa foi uma experiência que me marcou muito ${ }^{21}$.

Podemos ver neste relato como a artista começa, a partir de uma demanda específica, a desenvolver algo em que não havia pensado anteriormente, algo de inédito para ela. Moldado para a ocasião específica, o workshop teve um caráter experimental e parte dos elementos da criação artística ao qual a companhia estava se dedicando naquele momento.

Já quando ministraram oficinas para alunos de várias escolas estaduais e municipais do Rio de Janeiro, Lia e os integrantes da companhia construíram um conjunto de atividades capazes de dar conta de faixas etárias diferentes simultaneamente, pois para a surpresa da artista de sua equipe as turmas eram mistas e muito numerosas, reunindo crianças e adolescentes. Essa experiência obrigou-os a desenvolver propostas diferentes das que haviam utilizado até então. Ela ressalta que, para cada grupo, cria-se uma metodologia diferente, de acordo com os objetivos da aula e as características do grupo. Nas palavras da coreógrafa:

Ali a gente aprendeu muito a construir uma outra metodologia. Parece que pra mim, são metodologias muito diferentes para cada grupo, né? Imagina estar como professora de uma certa faixa etária e, de repente, numa escola, onde também não tinha nenhum espaço para a dança, abrem uma porta e entram cem alunos, de faixas etárias diferentes! E a gente fazia pequenos grupos, esses pequenos grupos se encontravam, a gente tinha uma mesma sequência de exercícios, e depois a gente juntava todo mundo ${ }^{22}$.

Podemos identificar aqui o "choque com a realidade" mencionado por Tardif. Diante de uma realidade com a qual não contava, e para a qual não estava de fato preparada, Lia se vê impulsionada a encontrar e a desenvolver saberes próprios, alicerçados em suas
20.

Entrevista concedida a Silvia Soter. Lausanne, 9 de dezembro 2016.

21.

Entrevista concedida a Silvia Soter. Lausanne, 9 de dezembro 2016.

22.

Entrevista concedida a Silvia Soter. Lausanne, 9 de dezembro 2016. 
práticas anteriores, e a, neles, ancorar seu trabalho. Um trabalho dinâmico, sempre em constante renovação.

A artista declara que imaginava que, um dia, chegaria a escrever algo que pudesse usar em todos os seus workshops, uma espécie de manual ou apostila. Sua ideia era criar uma metodologia, um roteiro que, ao longo dos anos, pudesse utilizar nas várias situações de ensino. Mas, com o passar dos anos, ela constatou não ser possível:

Eu percebi que nenhuma [metodologia] funcionava pra outra [aula]. Que, a cada vez, eu tinha que inventar alguma coisa. A gente até tem isso, um reservatório de milhares de procedimentos que a gente já usou em milhares de workshops. E isso é muito legal. [...] E eu sempre nesse sonho... [risos] de que eu pudesse ter um [livro] [...]. Imagina se é assim, né? Eu queria ter umas fichas [...] mas eu tenho que aceitar que a cada vez tenho [que recomeçar] [...]. eu me sinto muito despossuída, muito despreparada, a cada vez, para dar uma aula, como se eu tivesse que começar do zero ${ }^{23}$.

Como assume inúmeras vezes, dar aulas produz ansiedade em Lia Rodrigues; a sensação de despreparo está constantemente presente nessas ocasiões. Para lidar com a ansiedade, a cada vez que deve dar aulas, workshops ou cursos de duração variada, ela necessita de preparação.

\section{Planejamento}

Para planejar as aulas, lutando contra essa sensação de estar "despossuída", a coreógrafa diz ler repetidamente os registros de cursos que já deu, pois tem a prática de anotar e registrar por escrito o que realiza nas aulas. Quando indagada sobre a razão de revisitar os registros de aulas anteriores, a artista diz: "[...] eu escrevo muito. Tenho feito, nos últimos anos, um relato de cada dia dos meus trabalhos com estudantes, porque isso me ajuda a organizar meu pensamento pro dia seguinte. Mas depois eu não lembro nada do que eu já fiz, que escrevi, que inventei”24. Voltar a esses registros a ajuda a recuperar algumas experiências que, muitas vezes, são propostas a outros grupos. Além de seus próprios registros, diz preparar-se lendo diferentes textos, assim como voltar à leitura de autores que a inspiram, como explica:

23.

Entrevista concedida a Silvia Soter. Lausanne, 9 de dezembro 2016.
24.

Entrevista concedida a Silvia Soter. Lausanne, 9 de dezembro 2016.
Eu leio coisas que de repente passam pela minha cabeça. Leio um texto, uma poesia... [Me pergunto] eu estou lendo essa poesia por quê? Porque eu estou me inspirando, eu estou me alimentando 
para me sentir inspirada, instigada criativamente. Quando [eu leio] uma poesia, ela me instiga em todos os níveis: técnico, poético, criativo. Como é que a autora escreveu isso? Como ela teve essa ideia, como é que ela dividiu essa poesia assim, em dois a dois, e três? Parece que fico boiando em um monte de coisas.

Imersa, ou melhor, como ela mesma diz, "boiando" nessas leituras que misturam registros de aulas anteriores e inspirações diversas, Lia Rodrigues prepara suas aulas, busca encontrar um "estado" para dar aulas. Ela não prepara necessariamente a aula, mas se prepara para estar na posição de artista-professora. No dia da aula, diz acordar muito cedo e escrever em folhas soltas, à mão, as ideias e propostas que pretende desenvolver. Essa prática é a mesma que tem quando está em processo de desenvolvimento de uma nova obra. O modo como se prepara para dar aulas é muito próximo do modo como se organiza antes dos ensaios junto a sua companhia, como afirma:

\begin{abstract}
Pra mim, dar uma aula é uma criação. E eu me preparo [de modo] parecido com que eu me preparo para uma criação, da mesma forma que eu planejo a minha ida pra Maré, quando eu tenho que fazer um trabalho. Eu acordo muito cedo, escrevo muita coisa. [Tenho que] me colocar em estado [...] e também preciso olhar para cada um, preciso entender com quem eu estou trabalhando. Preciso criar uma empatia ${ }^{25}$.
\end{abstract}

Ao longo da entrevista realizada com a artista, vemos surgir em sua fala termos como "boiar", "banho", "estado", ou "empatia" - todos termos que nos remetem a uma entrada em um modo de estar específico, buscado tanto em situação de criação, quanto em situação docente. Para alcançar esse modo, ela se prepara, se concentra, fabrica um modo de ser-e-estar-em-trabalho. Aos poucos, Lia-professora criou uma forma de entrar, junto com seus estudantes, nessa aula-estado.

\section{Objetivos e desafios}

Quando indagada sobre quais são seus objetivos ao ensinar, a coreógrafa afirma que prefere não os ter, pois acredita que, quando estabelece um objetivo preciso, perde a criatividade. Ela afirma ter que "estar o tempo inteiro em invenção". E ainda: "Se eu falar: eu quero chegar ali, pronto, já morreu"26. Por isso, as aulas funcionam como um laboratório. A coreógrafa propõe ao grupo algumas experiências que servem de ponto de partida e, à medida
Entrevista concedida a Silvia Soter. Lausanne, 9 de dezembro 2016.
Entrevista concedida a Silvia Soter. Lausanne, 9 de dezembro 2016. 
que são desenvolvidas pelo grupo, ela intervém e as transforma. Mesmo sem um planejamento fechado, à medida que as propostas evoluem, "um caminho se abre", diz a coreógrafa.

Para Lia, suas aulas-laboratório são mais interessantes quando os alunos, estimulados por ela, conseguem de fato colaborar como grupo. Assim como ocorre em suas criações, junto à companhia de dança, o grupo é um elemento central em seu trabalho de ensino, como destaca:

Quando todo mundo começa a trabalhar junto, é onde a coisa rola melhor. Eu sempre acho isso, eu sempre acho o grupo o lugar onde a minha criatividade vem, sabe? O grupo é uma coisa que eu acho legal. Essa troca... as pessoas diferentes que propõem coisas que eu nunca imaginava, [...] eu trabalho com pessoas cada vez mais jovens, né? Então, isso é muito bom pra mim, isso abre muito a minha cabeça e, ao mesmo tempo, eu venho com uma experiência pra juntar com a juventude deles, né? ${ }^{27}$

Mas isso não é sempre possível. Lia Rodrigues aponta que seu maior desafio é dar aulas para artistas que já têm um trabalho próprio, que estão em momento mais avançado em suas práticas artísticas, pois, em geral, estão menos dispostos a novas formas de colaboração. Ela avalia:

Eu acho que trabalhar, fazer com que o grupo trabalhe junto, é muito mais fácil quando você trabalha com um grupo que não tem ainda seu próprio trabalho. Quando eu vou trabalhar com gente que já tem seus caminhos, isso é muito mais difícil. Porque é muito difícil abrir mão e fazer um projeto comum. O que é sempre a minha proposta ${ }^{28}$.

Como vimos, para lidar com os muitos desafios encontrados ao dar uma aula ou oficina, a artista recorre a uma preparação de si mesma, colocando-se em um estado específico e procurando se nutrir para cada ocasião. Além disso, determinadas estratégias a auxiliam a entrar em contato direto com os alunos, preparando o terreno para as suas propostas e intervenções. Vejamos como isso ocorre.

\section{As aulas}

As rodas de conversa: apresentação e empatia

Os cursos e as oficinas de Lia Rodrigues se iniciam por conversas, e não - como é recorrente em aulas de danças - por alguma ati-
27.

Entrevista concedida a Silvia Soter. Lausanne, 9 de dezembro 2016.

28.

Entrevista concedida a Silvia Soter. Lausanne, 9 de dezembro 2016. 
vidade de aquecimento mais física, que ela diz não valorizar: "eu não trabalho assim, eu não sei trabalhar com isso, com aquecimento. Acho que a gente tem que se aquecer mentalmente, pra poder depois fazer as coisas, aquecer a criatividade"29. Os alunos, sentados em roda, devem se apresentar, falar de seus percursos até aquele momento e de suas expectativas em relação ao curso e, no caso da oficina ministrada no intercâmbio com La Manufacture, citar artistas cujas obras admiravam. Começar as oficinas por uma roda de conversa serve também para que se instale um outro estado de espírito nos estudantes, uma preparação do terreno para que as propostas de Lia Rodrigues se desenvolvam. Mas isso nem sempre é fácil, como ela explica neste longo trecho a seguir:

A gente tem que ter paciência porque, quando são muitos alunos, demora muito pra todo mundo se apresentar! Todo mundo fica inquieto, é chato, porque bailarino gosta de se mover. Ainda mais os jovens... eles amam, porque têm energia pra gastar! E eu não trabalho com essa energia, trabalho com uma outra energia. É o mesmo jeito de trabalhar com criação, no meu caso. É árido. É muito árido, muito seco. Essa aridez inicial é pra gente poder pirar depois. É como se eu tivesse um monte de cavalos fogosos - esses estudantes - e eu prendo a rédea. Eu prendo essa rédea porque eu acho que precisa dar uma desligada dessa coisa de produzir, produzir, produzir, produzir, produzir, produzir movimento, ficar dançando, levantando a perna, assim. Eu fico atordoada com isso. Eu dou uma freada nisso pra pessoa poder ir para um outro lugar dentro de si, para pensar de outra forma, que se mover pode vir de outro lugar, pra gente poder brincar muito mais. É que eu acho que isso não é uma aridez, acho que não é uma boa palavra. Pra mim, é aquela parte de plantar que você fica, assim, preparando a terra. E preparar a terra dá trabalho. É arar, fazer sulcos... não é assim só pegar e jogar um monte de sementes ${ }^{30}$.

Conhecer os alunos, seus percursos, interesses e expectativas é fundamental para Lia Rodrigues. Essas conversas ajudam a artista a construir uma espécie de diagnóstico do grupo. É só a partir desse momento inicial de apresentação que ela confirmará, tomará a decisão final sobre o que será desenvolvido na oficina. Frustrá-los, impedindo que se movimentem para que encontrem outra "energia", é estratégico para a artista, para que os estudantes encontrem novas possibilidades criativas. A apresentação dos alunos é um primeiro passo para levar a esse outro estado e também para a construção do que chama de "empatia". O passo seguinte é o momento em que ela apresenta seu próprio percurso profissional, entrelaçado com aspectos de sua biografia. Além de conter o impulso de se movimentar dos estudantes para que se estabeleça um outro estado para o trabalho, as rodas de conversa
29.

Entrevista concedida a Silvia Soter. Lausanne, 9 de dezembro 2016.
30.

Entrevista concedida a Silvia Soter. Lausanne, 9 de dezembro 2016. 
têm outros interesses para a artista. Ela apresenta algumas razões para que dispense tantas horas do curso nesta roda de conversa:

Quando as pessoas falam, consigo enxergar, através do que elas falam, seus desejos, contradições, desconfianças, disponibilidades. Isso é muito claro para mim. É só experiência. A gente vai ver quem fala mais, quem fala menos. Depois eu conto a minha história. Quando eu conto a minha história, eu tento chamá-los para mim. Eu conto, mostro imagens do que eu faço, do meu trabalho, porque as pessoas se conhecem pouco. Eu parto do conhecimento um do outro. Eu necessito criar esse momento de empatia entre as pessoas e em torno do meu trabalho também, pra gente saber em que terreno está pisando. Eu posso medir um pouco, posso falar um pouquinho sobre política, falar um pouquinho sobre diferença. Nessas conversas, eu procuro tocar nesses pontos ${ }^{31}$.

Quando os grupos são grandes, essas conversas podem ocupar de dois a três dias do workshop, uma vez que a artista também dedica algumas horas a apresentar seu percurso profissional, entrelaçado à sua vida pessoal, e mostra trechos de suas obras aos alunos. No caso do workshop na La Manufacture, as conversas iniciais ocuparam dois dias e meio do curso. A prática de iniciar um workshop com uma coreógrafa por conversas parece ser pouco usual para os estudantes.

\section{Olhar dos alunos}

Um dos alunos da La Manufacuture, que chamaremos aqui de Aluno 4, quando indagado sobre o que destacaria da primeira semana de trabalho com Lia Rodrigues, relata:

O que eu realmente guardei dessa primeira semana [...] [foi] a relação com a linguagem, porque a gente falou muito, e isso não nos acontece frequentemente nos workshops de dança. [...] eu vi que a gente pode realmente se colocar em volta de uma mesa e falar, e depois isso pode servir de verdade para a criação [...] E também o fato de que ela nos apresentou seu trabalho, acompanhar sua carreira é interessante para nos dar ideias [...] e além disso, uma relação bastante íntima foi criada entre ela e nós ${ }^{32}$.

Para este aluno, apesar de não habituais, as conversas foram inspiradoras para as propostas de investigação e criação que se seguiram, e também para que se criasse uma relação mais íntima entre os alunos e a coreógrafa, próxima talvez do que a artista chama de criar "empatia" para que possa iniciar o trabalho. Essa relação de proximidade com os alunos é também é percebida
31.

Entrevista concedida a Silvia Soter. Lausanne, 9 de dezembro 2016.
32.

Aluno 4. Entrevista do grupo de alunos do bacharelado de dança da La Manufacture concedida a Silvia Soter. Lausanne, 16 de dezembro de 2016. 
como marcante e positiva pela Aluna 9. Ela destacou a "conexão humana" como um ponto forte do workshop e uma característica de Lia Rodrigues:

O que se destacou para mim foi a conexão humana, a vida que ela dá aos elementos, aquilo que, de fato, já está na sala de aula. Quero dizer, nós, nossa personalidade, nossa imaginação, os objetos dentro da sala, o espaço, as conexões que existem entre nós, nosso saber. Ela pôde tomar tempo, ela usou uma manhã inteira para que a gente pudesse falar de nós mesmos. [...] Então, a gente toma o tempo de saber realmente quem nos inspira, a gente repara que todo mundo tem inspirações, que todo mundo tem inspirações diferentes. E que tudo isto é uma bagagem, uma bagagem coletiva que podemos utilizar. E é como se isso refrescasse cada pessoa, e isso dá vida novamente, e isso permite que se utilize as particularidades da situação. Isso foi o que eu guardei desse estágio, como uma regara absoluta, que toda situação é particular, é um caso específico. E que existe caráter em cada uma das situações ${ }^{33}$.

Para a Aluna 5, a impressão é de que Lia Rodrigues "era levada pela maré", o que a agradou. Ela explica a razão:

Gostei muito, porque ela estava fazendo o que era necessário, de uma certa forma, e acho que ela também estava muito, muito aberta. Então, eu não tive a sensação que ela estava nos impondo uma forma de se fazer as coisas, apesar dela ter compartilhado conosco sua maneira de trabalhar e seus trabalhos. Mas sempre de um jeito muito aberto. Isto era encorajador, confiar na nossa espontaneidade, nos nossos interesses, nossas ideias ${ }^{34}$.

Afirmar a capacidade dos alunos de criar de forma autônoma e apoiá-los em seus caminhos criativos são lembradas pelos alunos como características do trabalho de Lia Rodrigues, como vemos no relato do Aluno 6: "Eu acho que tinha uma grande parte do trabalho que era para ser feita por nós mesmos, e que a questão era como abrir um pouco as portas, e, depois, ver como é que nós interpretamos e pegamos o que ela nos deu, e como isso nos fez pensar"35.

Um exemplo dessa forma de se trabalhar se vê no workshop que aconteceu na La Manufacture. A primeira proposta feita ao grupo foi a de que se dividissem em duplas e que cada um escolhesse cinco objetos que estivessem disponíveis na sala (do mobiliário ou objetos pessoais). Em seguida, um a um, deviam posicionar esses objetos numa pequena composição. Como um laboratório, esta primeira proposta ganhou vários desdobramentos, até que o grupo inteiro passou a colaborar em conjunto para uma mesma composição dos diversos objetos. O Aluno 12 considera
33 .

Aluna 9. Entrevista do grupo de alunos do bacharelado de dança da La Manufacture concedida a Silvia Soter. Lausanne, 16 de dezembro de 2016.

34

Aluna 5. Entrevista do grupo de alunos do bacharelado de dança da La Manufacture concedida a Silvia Soter. Lausanne, 16 de dezembro de 2016.

35.

Aluno 6. Entrevista do grupo de alunos do bacharelado de dança da La Manufacture concedida a Silvia Soter. Lausanne, 16 de dezembro de 2016. 
esse exercício o mais marcante das duas semanas de trabalho com a coreógrafa e destaca a relação percebida por ele entre a proposta e algumas obras de Lia Rodrigues assistidas pela turma em vídeo nos primeiros dias da oficina:

Como tornamos preciosas coisas tão simples, a que normalmente não damos importância, como uma caneta, ou outra coisa! Como a gente constrói alguma coisa a partir de nada, e que coisa bacana sai dali! A imaginação, ela entra em jogo, a criatividade. De novo, a gente pode criar histórias a partir de quase nada. $\mathrm{E}$ isso me lembra também o que eu vi nas peças da Lia, como ela utiliza o plástico, as coisas simples, o acessório, tantas vezes tão elementar. E, novamente, coisas tão belas surgem... humanas. Esse exercício me marcou de verdade, porque era uma composição com quase nada, e que pode levar longe ${ }^{36}$.

\section{A estrutura é sair da estrutura}

Beleza e simplicidade, riqueza e poucos recursos, espontaneidade e organização, precisão e caos, força e fragilidade, noções aparentemente opostas, em muitos casos incompatíveis, são sublinhadas na fala dos alunos como características das aulas de Lia Rodrigues e da própria artista, como vemos nos trechos a seguir:

A primeira coisa que me vem à mente é a espontaneidade... eu realmente vi uma maneira de ensinar super espontânea. E, ao mesmo tempo, organizada, porque a gente vê que ela se preparou, que ela sabe. Mas é como se ela tivesse uma bagagem enorme, uma mala enorme que trouxe com ela, e que colocou tudo isso à disposição, que ela tem confiança nas coisas que tem à sua disposição. Então, ela toma a temperatura do que acontece na sala de aula, e ela tira da mala isso, e isso, bom, hoje a gente vai falar de camisa, então pega uma camisa, hoje de calças, pega as calças. [...] é realmente... super espontâneo! O que é bacana é que, ao mesmo tempo, cada tema e cada coisa que ela traz, a gente pode aprofundar enormemente, e isso pode nos levar a algo completamente diferente. Eu gostei muito dessa liberdade que a gente tinha de não ter medo de sair da estrutura, porque a estrutura era, em si, sair da estrutura ${ }^{37}$.

Em seguida, a Aluna 3 ressalta a preocupação da artista com a clareza e precisão dos propósitos nos exercícios:

Lia era sempre precisa e sempre disse que temos que ser cuidadosos com as coisas. Apesar dela criar situações caóticas, apesar de que algumas vezes parecia uma bagunça, era muito importante
36.

Aluno 12. Entrevista do grupo de alunos do bacharelado de dança da La Manufacture concedida a Silvia Soter. Lausanne, 16 de dezembro de 2016.

37.

Aluno 1. Entrevista do grupo de alunos do bacharelado de dança da La Manufacture concedida a Silvia Soter. Lausanne, 16 de dezembro de 2016 . 
cuidar das coisas. [...] Mas a gente podia sempre sentir que ela queria que fosse tudo claro e também preciso ${ }^{38}$.

Finalmente, vemos na próxima fala o impacto que a figura de Lia Rodrigues, descrita aqui como humilde, frágil, porém cheia de força, teve no Aluno 9:

A gente tem a impressão que ela sabe tudo e, ao mesmo tempo, ela tinha uma tamanha humildade! [...] A gente tem a impressão de que ela tem uma força sem fim e, ao mesmo tempo, uma fragilidade. E ela nos mostra também essa fragilidade, se a gente ousar colocá-la contra a parede, isso se torna um parâmetro da situação, isso se torna uma restrição criativa, se torna uma força ${ }^{39}$.

\section{Considerações finais}

Ainda que não reconheça ter desenvolvido uma metodologia de ensino apoiada sempre em um mesmo conjunto variado de estratégias de ensino, que poderiam ser "aplicadas" a todos os contextos em que ensina, e materializada nas tais "fichas" que um dia sonhou possuir, de nosso ponto de vista, Lia Rodrigues vem, sim, constituindo uma metodologia de ensino própria a partir de seus saberes experienciais. Entende-se, aqui, metodologia como um caminho para se atingir um fim.

Tributárias de sua vivência de aluna de balé clássico em escolas técnicas e cursos livres, e sustentadas em saberes edificados na trajetória pré-profissional, segundo a perspectiva de Tardif, as práticas docentes iniciais de Lia Rodrigues se transformaram, pouco a pouco, em um modo singular de abordar a dança e o ensino de dança, sustentado pelos saberes experienciais. Sua concepção de aula de dança se transformou, abandonando a visão de que ensinar dança é sinônimo de ensinar uma técnica específica, e se aproximou de abordagens que permitam a formação de artistas da dança de modo mais integral.

Como alguém que cedo começou a participar como intérprete de uma companhia profissional de dança contemporânea, a Companhia Maguy Marin, e que desde 1985 tornou-se também coreógrafa, poucos anos mais tarde passando a dirigir sua própria companhia de dança, Lia Rodrigues entrelaça seus saberes de artista-criadora à sua prática quando em situação pedagógica. Não tendo ela própria passado por programas de formação docente em dança ao longo de seu percurso profissional, foi experimentando modos de ensinar a dança, nos quais as questões e os métodos de criação mobilizados na construção de suas peças constituíram-se
38.

Aluna 3. Entrevista do grupo de alunos do bacharelado de dança da La Manufacture concedida a Silvia Soter. Lausanne, 16 de dezembro de 2016.

39.

Aluno 9. Entrevista do grupo de alunos do bacharelado de dança da La Manufacture concedida a Silvia Soter. Lausanne, 16 de dezembro de 2016. 
como elementos centrais. Os saberes de sua trajetória pré-profissional foram perdendo lugar para dar espaço aos saberes práticos (TARDIF, 2012), sobretudo os saberes da experiência.

A valorização do grupo como base para a colaboração criativa, o partir de jogos simples para o desenvolvimento de laboratórios de exploração da criatividade e a centralidade das rodas de discussão são alguns dos elementos que estão presentes tanto no trabalho de criação junto à Lia Rodrigues Companhia de Danças, quanto na sua atuação em situação pedagógica. Comuns ao ensinar e ao criar, a forma como se prepara para os ensaios e as aulas, a necessidade de ver e rever suas notas, a confiança na autonomia dos grupos e que das propostas decorrerá material a partir do qual fará suas intervenções são constantes na prática de Lia Rodrigues. Para a artista, criar e ensinar se comunicam. Ela acredita que se colocar em situação pedagógica tendo jovens em formação como alunos tem impacto positivo sobre o que faz:

É muito legal porque eu tenho que me recolocar sempre, ali, com eles [os alunos]. Me coloco muito numa situação de reconsiderar as coisas que eu penso e o que eu sou. E eu acho que as minhas criações, depois que eu trabalho com esses grupos, são muito influenciadas pelo meu trabalho de professora, vamos dizer assim: alimenta a minha criação e a criação alimenta o ensinar. é uma coisa, assim, que troca sem parar ${ }^{40}$.

40.

Entrevista concedida a Silvia Soter. Lausanne, 9 de dezembro 2016.

o que é, Lia Rodrigues cria um caminho de mão dupla entre a sua prática de criação artística e a sua prática como professora. Nesse entrelaçamento, vemos as colocações de Tardif tomarem corpo em exemplo claro de mobilização de saberes oriundos de uma longa trajetória, em prol tanto da criação, quanto do ensino. Podemos ver igualmente a forma como tal prática reverbera nos alunos através das muitas falas reproduzidas aqui. A criação alimentando o ensinar, e o ensinar alimentando a criação, "uma coisa, assim, que troca sem parar"! 
BORGES, Cecília. O professor da educação básica de 5a. a 8 a. série e seus saberes profissionais. Rio de Janeiro, 2002. Tese (Doutorado em Educação) - Departamento de Educação, Pontifícia Universidade Católica do Rio de Janeiro, Rio de Janeiro, 2002.

MARQUES, Isabel. O artista/docente: ou o que a arte pode aprender com a educação. Ouvirouver, Uberlândia, v. 10, n. 2, p. 230239, jul/dez 2014.

MONTEIRO, Ana Maria Ferreira da Costa. Professores: entre saberes e práticas. Educação \& Sociedade, ano XXII, n. 74, abr. 2001.

MUNDIM, Ana Carolina. O artista docente em dança: discursos e práticas. Ouvirouver, Uberlândia, v. 10, n. 2, p. 191-193, jul/dez 2014. NUNES, Célia Maria Fernandes. Saberes docentes e formação de professores: um breve panorama da pesquisa brasileira. Educação \& Sociedade, ano XXII, n. 74, abr. 2001.

PAVLOVA, Adriana. Dança e Política:Movimentos da Lia Rodrigues Companhia de Danças na Maré. Dissertação (mestrado) - UFRJ / Escola de Comunicação / Programa de Pós-Graduação em Artes da Cena, 2015.

PEDALINO, Carolina. Brésilianités, de la naissance de la notion à l'analyse de Folia et Pororoca, de L. Rodrigues. Dissertação (mestrado) Université Paris VIII Saint-Denis U F R Arts, Esthétique et Philosophie MASTER Arts, mention Musique, Spécialité : Danse. 2010.

PIMENTA, Selma Garrido. Formação de professores: identidade e saberes da docência. In: PIMENTA, Selma Garrido (Org.). Saberes Pedagógicos e atividade docente. São Paulo, Cortez, 2012. 8. ed.

SOTER, S. Saberes Docentes para o Ensino da Dança: Relação entre saberes e formação inicial de licenciados em Dança e Educação Física que atuam em escolas da rede pública de ensino do Rio de Janeiro e da região metropolitana. Rio de Janeiro. Tese PPGEC, Faculdade de Educação, Universidade Federal do Rio de Janeiro. Rio de Janeiro, 2016.

SOTER, S., PAVLOVA, A. Escola Livre de Dança da Maré in Rio de Janeiro: a ground to share. In: BUTTERWORTH, J., WILDSCUT, L. Contemporary Choreography: A Critical Reader, Londres \& Nova Iorque: Routledge, 2017, p. 268-278.

STEUERNAGEL, Marcos. Lia Rodrigues - dançando cartografias de resistência nas favelas do Rio de Janeiro. New York: New York University. Departamento de Estudos da Performance, Doutorando, Orientador André Lepecki. 2012

TARDIF, Maurice. Saberes docentes e formação profissional. Petrópolis: Vozes, 2012. 14. ed. 